\title{
BOMBEAMENTO DE ÁGUA NO MEIO RURAL UTILIZANDO UM CARNEIRO HIDRÁULICO DE BAIXO CUSTO
}

\author{
Niedja Bezerra Costa1; Raphael Pereira da Silva²; Wilson Araújo da Silva ${ }^{3}$ \\ ${ }^{1}$ Discente do Curso de Agronomia da Universidade Estadual do Maranhão, Campus Cesi, flordllis_87@hotmail.com \\ 2 Eng. Agr. da Universidade Estadual do Maranhão, Campos Cesi \\ 3Prof. D.Sc. Adjunto I, Departamento de Química e Biologia, Universidade Estadual do Maranhão, Centro de Estudos \\ Superiores de Imperatriz - CESI
}

RESUMO: A recente crise da energia convencional tem ocasionado a exploração de fontes alternativas de energias para suprir usos doméstico, industrial e agrícola. $\mathrm{O}$ carneiro hidráulico ou aríete hidráulico é uma máquina simples que possui características geratriz e operatriz. A fonte de energia é a altura de queda d'água que, em geral, é produzida artificialmente por meio de pequena barragem. O bombeamento de água utilizando carneiro hidráulico é amplamente empregado em muitas propriedades, principalmente onde a energia elétrica é escassa ou inexistente. A metodologia utilizada na construção do equipamento está de acordo com CERPCH/2002. Com base nos resultados encontrados pode-se concluir que o equipamento representa uma opção alternativa de bombeamento de água no meio rural para pequenos produtores em regiões desprovidas de energia elétrica. Os custos de montagem, comparado com o carneiro convencional compatível com o $\mathrm{N}^{\circ} 1$ foi abaixo de $20 \%$.

PALAVRAS-CHAVE: golpe de aríete, irrigação, sustentabilidade.

\section{PUMPING WATER IN RURAL AREAS USING A HYDRAULIC RAM LOW COST}

\begin{abstract}
The recent conventional energy crisis has caused the exploitation of alternative energy sources to meet domestic uses, industrial and agricultural. The hydraulic ram or hydraulic ram is a simple machine that has features and generating tool. The energy source is the height of fall of water that, in general, is produced artificially by a small dam. The pumping of water using ram pumps is widely used in many properties, especially where electricity is scarce or no inexistent. The methodology used in constructing the equipment complies with CERPCH/2002. Based on these results we can conclude that the equipment represents an alternative option of pumping water in rural areas to small farmers in regions devoid of electricity. Assembly costs compared with conventional ram compatible with the $\mathrm{N}^{\mathrm{o}} 1$ was below $20 \%$.
\end{abstract}

KEY-WORDS: irrigation, sustainability, water hammer.

\section{INTRODUÇÃO}

Atualmente no mundo globalizado, há escassez de energia e de água de boa qualidade. Fato que acarreta aumento dos custos da produção agrícola, devido ao aumento dos valores quer de energia quer de insumos. Considerando que qualquer empreendimento somente será economicamente viável se seus benefícios econômicos forem maiores do que os custos têm-se que melhorar a eficiência de uso da água na irrigação.

O funcionamento do carneiro hidráulico é decorrente do golpe de aríete causado pelo fechamento de uma válvula, que interrompe o movimento da água proveniente de uma fonte de alimentação localizada em nível superior. O fenômeno do golpe de aríete 
é de natureza complexa, cuja determinação é importante para a aplicação de medidas preventivas em situação onde este pode provocar avaria ao sistema de adução (AZEVEDO NETTO, 1969).

É de capital importância que se tenha consciência de que a irrigação como prática isolada não propiciará os benefícios desejados. Esta deve ser acompanhada de outras práticas culturais para gerar os lucros esperados da agricultura irrigada, tais como: variedades produtivas e de bom valor comercial, adubações, tratos culturais apropriados, etc. Nas regiões onde se investiu em irrigação, ocorreu desenvolvimento econômico, desenvolvimento social e, consequentemente redução de pobreza. Notadamente quando as ações foram integradas, seqüenciais e em tempo hábil, permitindo a consolidação da corrente produtiva e a sustentabilidade de mercado para os produtos.
O objetivo deste trabalho foi propor uma maneira alternativa de captação de água no meio rural, utilizando o carneiro hidráulico, sem a utilização de energias não renováveis (energia elétrica e combustíveis fósseis) com o propósito de atender as necessidades hídricas de pequenos produtores rurais.

\section{MATERIAL E MÉTODOS}

A construção do equipamento foi realizada no laboratório de Agronomia da UEMA/CESI, seguindo as orientações propostas por CERPCH (2002), os testes de desempenho hidráulico foram realizados em uma propriedade agrícola localizada no sudoeste do Estado do Maranhão, próximo à cidade de Imperatriz-MA. Para construção do equipamento proposto neste estudo, além da garrafa pet, foram utilizados tubos e conexões hidráulicas de baixo custo, conforme apresentados na Quadro 1.

Quadro 1. Materiais hidráulicos utilizados na construção do carneiro hidráulico de baixo custo.

\begin{tabular}{|c|c|c|c|c|}
\hline \multirow[t]{2}{*}{ Quant. } & \multirow[t]{2}{*}{ Material } & \multicolumn{3}{|c|}{ Diâmetro de entrada } \\
\hline & & 1", & 2"” & 3"' \\
\hline 01 & Garrafa Pet 2 litros & 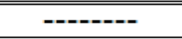 & 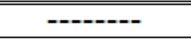 & +-on \\
\hline 01 & Tampa de garrafa com furo $\varnothing 15 / \mathrm{mm}$ & ------ & ---o- & --on \\
\hline 01 & Bucha redução & ------ & $1 " x 3 / 4 "$ & $2 " x^{3 / 4}$, \\
\hline 01 & Tê PVC branco rosca & $3 / 4, "$ & $1 "$, & $1 "$ \\
\hline 01 & Bucha redução PVC branco rosca & $3 / 4 "$ X $1 / 2 "$ & $1 "$ x $3 / 4 "$ & $2 " \times 1 "$ \\
\hline 01 & Adaptador preto para mangueira & $1 / 2 "$ & $3 / 4$, & $1 "$, \\
\hline 01 & Niple PVC branco & $3 / 4^{\prime \prime}$ & $1 \%$ & $2 "$ \\
\hline 01 & Bucha redução PVC branco rosca & $1 " x 3 / 4 "$ & $2 " \times 1 "$ & $3 " \times 1 "$ \\
\hline 01 & Válvula retenção vertical (topo Docol) & $1 \%$ & 2" & $3 \%$ \\
\hline 02 & Niple galvanizado & $1 "$, & $2 "$ & $3 \%$ \\
\hline 01 & Tê galvanizado & $1 "$ & $2 "$ & $3 "$ \\
\hline 01 & Válvula de poço Docol (latão Docol) & $1 \%$ & $2 "$ & $3 "$ \\
\hline 01 & Parafuso com três porcas e uma aruela & $5 / 16$ ou M8 & $5 / 16$ ou M8 & $5 / 16$ ou M8 \\
\hline 01 & $\begin{array}{l}\text { Mola do acionador da válvula de descarga para } \\
\text { vaso sanitário marca (hydra) }\end{array}$ & & & \\
\hline
\end{tabular}

Fonte: Thiago Neto (2008).

A Figura 1 apresenta os detalhes construtivos do equipamento. 


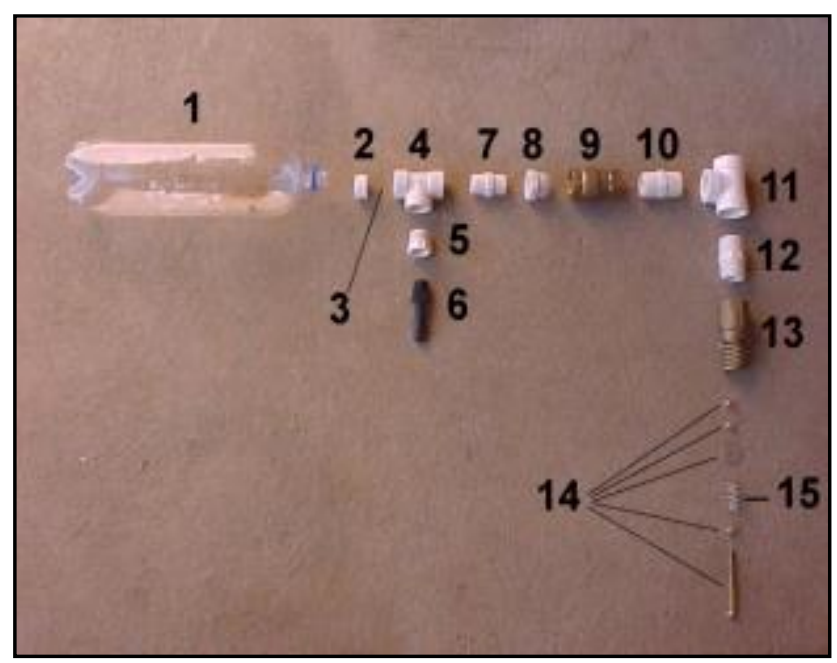

Figura 1: Detalhes construtivos do equipamento.

Fonte: CEPECH, 2002.

A avaliação hidráulica do equipamento foi realizada utilizando-se a equação 1. Esta equação permite calcular a porcentagem de aproveitamento da água e o rendimento do equipamento.

$$
q=Q\left(\frac{h}{H}\right) \cdot R
$$

Em que,

$\mathrm{q}=$ Vazão de água recalcada $\left(1 . \mathrm{h}^{-1}\right)$

$\mathrm{Q}=$ Vazão de alimentação $\left(1 . \mathrm{h}^{-1}\right)$

$\mathrm{h}=$ altura da queda disponível $(\mathrm{m})$

$\mathrm{H}=$ Altura de recalque $(\mathrm{m})$

$\mathrm{R}=$ Rendimento do equipamento (\%)

\section{RESULTADOS E DISCUSSÃO}

$\mathrm{O}$ equipamento quando instalado no campo, necessitou da construção de uma barragem para elevar o nivel de água em um córrego existente. O tubo de alimentação do carneiro hidráulico foi constituído por duas varas de cano de PVC de $50 \mathrm{~mm}$ de diâmetro e 6 metros de comprimento cada, sendo que uma extremidade saiu diretamente da barragem e na outra foi instalado o equipamento para se proceder aos testes de desempenho hidráulico (Figuras 2). 


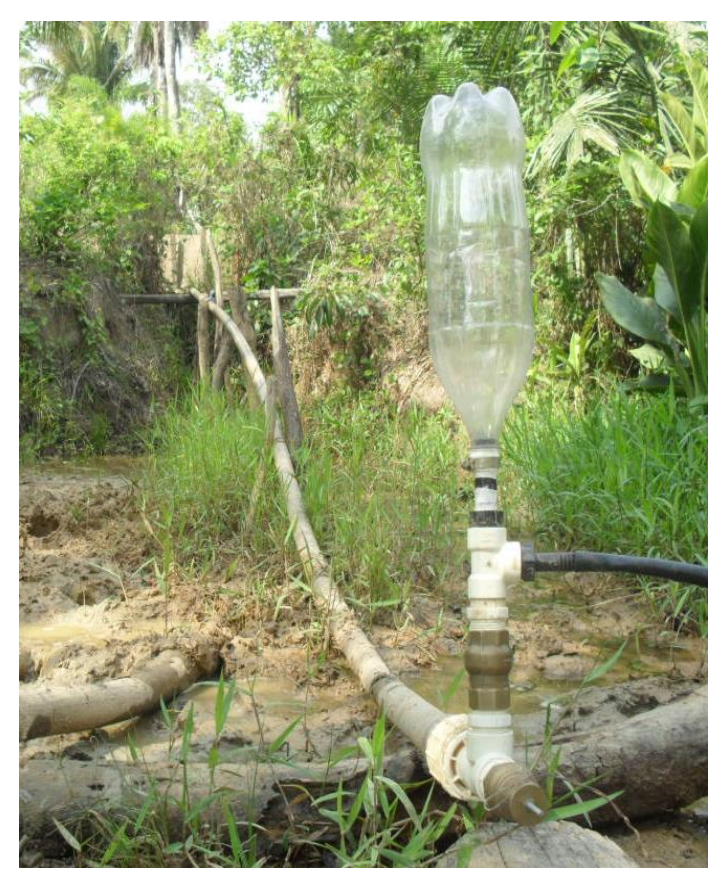

Figura 2: Instalação do equimamento no campo.

As medições de vazão realizadas no campo, mostraram uma vazão média recalcada de 4.285,07 L.dia ${ }^{-1}$, considerando um cenário hidráuico de: altura de recalque igual a 4,41 m, queda disponível de 1,45 m com uma carga hidráulica de $55 \mathrm{~cm}$, equivalente à altura da lâmina de água na barragem construída. Visando entender a relação altura de queda e altura de recalque, foram realizados testes de vazão considerando um outro cenário hidráulico, com uma altura de recalque de $6,41 \mathrm{~m}$. As medições de vazão média recalcada foi de 2.594 L.dia ${ }^{-1}$ (Quadro 2).

Quadro 2. Resultados do desempenho do equipamento no campo.

\begin{tabular}{ccccc}
\hline $\mathrm{h}(\mathrm{m})$ & $\mathrm{Lq}(\mathrm{m})$ & $\mathrm{H}(\mathrm{m})$ & $\mathrm{q}\left(\mathrm{L} \cdot d i a^{-1}\right)$ & Distancia bombeamento $(\mathrm{m})$ \\
\hline 2,00 & 12,00 & 4,41 & $4.285,07$ & 27,00 \\
2,00 & 12,00 & 6,41 & $2.594,00$ & 27,00 \\
\hline
\end{tabular}

\section{CONCLUSÃO}

Com base na análise dos resultados obtidos foi possível estabelecer as seguintes conclusões: $\mathrm{O}$ equipamento mostrou um funcionamento adequado quando testado no campo; Os custos de montagem, comparado com o carneiro convencional foi abaixo de 20\%; O equipamento representa uma opção alternativa de bombeamento de água no meio rural para pequenos produtores em regiões desprovidas de energia elétrica. 


\section{REFERÊNCIAS}

AZEVEDO NETTO, J. M. de Golpe de Ariete. In: ZAMBEL, A.R. Manual de aparelhos de bombeamento de água. São Carlos: USP/EESC, 1969. cap.10, p.183-209.

BHOI, K.L.; RAM S.; CHAUHAN. H.S.

Field evaluation of hydraulic rams. ICID

Bulletin, v.43, p.105-116, 1994.
MACINTYRE, A. J. Bombas e instalações de bombeamento. 2.ed. Rio de Janeiro: Ed. Guanabara Dois, 1980.

CERPCH - Centro Nacional de Referência em Pequenos Aproveitamentos Hidroenergéticos Av. BPS, 1303. Cx. P. 50 Itajubá - MG. CEP 37500-000. Fone: (035) 6291157 - Fax: (035) 6291265 